tree breeding. Theor. Appl. Genet. 93: 840-848 (1996). — JoHNSON, G. R. SNiEzko, R. N. and MANDEL, N. L.: Age trends in Douglas-fir genetic parameters and implications for optimum selection age. Silvae Genet 46: 349-358 (1997). - KING, J. N. and BuRDON, R. D.: Time trends in inheritance and projected efficiencies of early selection in a large 17 year old progeny test of Pinus radiata. Can J. For. Res. 21: 1200-1207 (1991). - LAMBETH, C. C.: Juvenile-mature correlation in Pinaceae and implications for early selection. For. Sci. 26: 571-580 (1980). — LAMBETH, C. and Dill, L. A.: Prediction models for juvenile mature correlations for loblolly pine growth traits within, between and across test sites. For. Genet. 8: 101-108 (2001). - Lambeth, C. C., van Buitenen, J. P., McCullough, R. B and Duke, S. D.: Early selection is effective in 20 year-old genetic tests of loblolly pine. Silvae Genet. 32: 210-215 (1983) - LindGren, D. and Werner, M.: Gain generating efficiency of different Norway spruce seed orchard designs. In: Proc. IUFRO WP S2.02-11 Meeting Norway spruce; Provenances, Breeding and Genetic Conservation (Eds. L.-G. STENER and M. WERNER), Uppsala, Sweden. pp. 189-207 (1989). - LindGREN, D. and Mullin, T. J.: Balancing gain and relatedness in selection. Silvae Genet. 46: 124-129 (1997). — LINDGREN, D. GeA, L. D. and Jefferson, P. A.: Status number for measuring genetic diversity. For. Genet. 4: 69-76 (1997). - Magnussen, S.: Growth differentiation in white spruce crop tree progenies. Silvae Genet. 28: 207
212 (1993). - McKeand, S. E.: Optimum age for family selection for growth in genetic tests of loblolly pine. For. Sci. 34: 400-411 (1988). NAMKOONG, G.: Optimum allocation of selection intensity in two stages of truncation selection. Biometrics 26: 465-476 (1970). - RIEMENSCHNEIDER, D. E.: Heritability, age-age correlations, and inferences regarding juvenile selection in Jack pine. For. Sci. 34: 1076-1082 (1988). - Rosvall, O.: Enhancing gain from long-term forest tree breeding while conserving genetic diversity. Dissertation, Swedish University of Agricultural Sciences, Umeå, Sweden, Sylvestria 109, (1999). Rosvall, O., Lindgren, D. and Mullin, T. J.: Sustainability robustness and efficiency of a multi-generation breeding strategy based on withinfamily clonal selection. Silvae Genet. 47: 307-321 (1999). — ROUSSET, F.: Inbreeding and relatedness coefficients: what do they measure? Heredity 88: 371-380 (2002). - WeI, R.-P. and LindGREN, D.: Optimum breeding generation interval considering build-up of relatedness. Can J. For. Res. 31: 722-729 (2001). - Wu, H. X.: Study of early selection in tree breeding - 1. Advantage of early selection through increase of selection intensity and reduction of field test size. Silvae Genet. 47: 146-155 (1998). - XIE, C.-Y. and YANCHUK, D.: Genetic parameters of height and diameter of interior spruce in British Columbia. For. Genet. 9: 1-10 (2002).

\title{
Retrospective Evaluation of Parental Selection in Nursery Tests of Juglans regia L. Using a Mixed Model Analysis
}

\author{
By N. Aletà ${ }^{1)}$, A. Ninot ${ }^{1)}$ and J. Voltas ${ }^{2)}$
}

(Received $31^{\text {st }}$ October 2003)

\section{Summary}

Results of early testing in Juglans regia performed over the period 1993-2002 are presented. A total of 37 progenies were evaluated for establishment, growth traits, and phenology at ages one and two during two or more sowing years in the nursery. Independent culling selection was applied on parental trees to the family-mean values using specific truncation points for establishment, diameter and total height. In addition, parental selection was performed on unbiased predictions (BLUPs) of parental breeding values using a multivariate mixed model analysis in order to account for the unbalanced nature of the entire data set. Genetic parameters (heritabilities, correlations) of juvenile traits were also estimated. Except for second year growth traits, the genetic control of most characters was quite high, with heritability estimates ranging from 0.51 (establishment) to 0.93 (flushing date). Growth performance and establishment did not bear a common genetic control according to non-significant genetic correlations, but a higher growth was typical of early flushing families. Changes in parental ranking for growth after comparison of familymean and BLUP-based estimates of parental performance were considerable. This observation, together with the larger proportion of culled progenies in the former method (about 70\%), suggests a sizeable loss of genetic gain by using unadjusted parental means. It is concluded that current evaluation and selection schemes using family-mean values should be recon-

1) Institut de Recerca i Tecnologia Agroalimentàries (IRTA). Departmen of Mediterranean Trees. Centre of Mas Bové. PO. Box 415. 43280 Reus. Spain.

2) Departament de Producció Vegetal i Ciència Forestal, E.T.S.E.A Universitat de Lleida, Av. Rovira Roure 191, Lleida E-25198, Spain sidered by i) relaxing truncation points for selection on establishment and growth traits and ii) re-evaluating progeny test data using a mixed model framework to unveil valuable material otherwise neglected due to unaccounted environmental influence on family performance.

Key words: Juglans regia, early selection, genetic parameters, BLUP, mixed model.

\section{Introduction}

Persian walnut (Juglans regia L.) is still present as scattered individual trees or in small groves in Western Europe (GERMAIN et al., 1997). Trees usually grow close to houses because of their traditional use to produce edible nuts. Although anthropic selection based on nut production has occurred since ancient times (Leslie and McGranahan, 1998), the use of Juglans regia wood is comparatively recent, starting in the fourteenth century with the creation of furniture manufactories in West Europe. Currently though, there is no improved material available in commercial forest nurseries for wood production in Europe. Most plantations are in fact established using seedlings from outstanding trees selected in surrounding areas. In Italy, wild populations such as 'Bleggiana' and 'Feltrina' in the north or 'Sorrento' in the south, have been traditionally used in plantations (MALVOLTI et al., 1996), while ancient cultivars characterised by their rusticity (e.g. 'Charente', 'Lozeronne') are still being planted in France (BECQUEY, 1997).

At present, breeding activities for Juglans regia are being carried out at Mas Bové (IRTA Centre, Spain) in order to release suitable material for wood production. Parental selection is undertaken through a two-stage scheme by which early 
screening of open-pollinated progenies performed in nursery tests is followed by extensive testing under environmental conditions closer to those commonly found in operational plantations (ALETÀ et al., 2003). Early testing is thus intended to discard deficient material rather than to select efficiently the best parent trees. Nursery selection in the first year is applied by considering three traits (establishment, diameter at $10 \mathrm{~cm}$ and total height) following general quality recommendations for walnut plants (BECQUEY, 1997) and usual requirements of commercial nurseries.

The opportunity of early testing has been extensively discussed by WU (1998). He points out three main advantages over longer-term selection procedures: i) increase of selection intensity and reduction of field test size; ii) shortened generation interval; and iii) implementation of genetic information from early evaluation to enhance selection efficiency at a mature age. Early testing therefore allows progenies with poor performance to be culled prior to field-testing, in which further parental evaluation is delayed until half the rotation age, i.e. 15 years in Juglans sp. (BRESNAN et al., 1992 and 1994). The effectiveness of early testing increases by choosing, whenever possible, appropriate traits (e.g. highly heritable and with good age-age correlations) and a similar environment to that found in operational plantations (MULLIN et al., 1995; Wu, 1998). For Juglans regia, information on genetic parameters (heritabilities and age-age correlations) is still lacking for predicting gains from early testing activities. In addition, previous results for Juglans nigra are inconsistent regarding the effectiveness of early testing due to large differences in the genetic performance of growth traits between field test locations (RINK, 1984; Rink and Clausen, 1989; BResnan et al., 1992; Rink and KunG, 1995).

Large unbalanced data sets are inherent to multi-year data derived from nursery evaluation of genetic entries varying over a number of years, as is the case for our breeding material. Adequacy of mixed models to evaluate such data structure has been widely recognised in plant breeding (WHITE and HodGE, 1989; PAtTerson, 1997; Frensham et al., 1998). The residual maximum likelihood (REML) algorithm allows for an accurate estimation of variance components that is crucial for (i) obtaining precise genetic parameters (heritability estimates, genetic correlations) to help define breeding strategies, and, (ii) predicting unbiased breeding values as the basis for ranking candidates and carrying out selection. In our breeding program, early testing of Juglans regia parents have been performed from 1993 to 2002 on the basis of independent culling for establishment, diameter and height. Based on this selection scheme, the aim of this study was to compare parental rankings of the traits of interest obtained by (i) averaging progeny performance following two-three sowing years of nursery testing for each progeny (conventional evaluation), and, (ii) deriving best linear unbiased predictions (BLUPs) of parental breeding values using a mixed model analysis on the entire data set. A second objective was to estimate genetic parameters (heritabilities, genetic correlations) of juvenile traits in order to redefine, if required, current protocols of data acquisition and/or selection strategy in the nursery.

\section{Material and Methods}

\section{Genetic material}

Seedlings of 35 Juglans regia progenies were obtained from open-pollinated autochthonous clones growing in field collections at Mas Bové - IRTA (Tarragona, Northeast Spain) where more than 80 clons from different origins are potential male genitors. The clones were selected, based on their outstanding phenotype, either from Spanish wild walnut populations (11 trees) or from different old walnut seedling orchards (24 trees). Two progenies from commercial cultivars were also evaluated: 'Chase D-9' (Oregon, USA) and 'Serr' (California, USA). The latter was taken as reference material because of its wellknown behaviour as Juglans regia rootstock in Spain.

\section{Nursery tests}

Progeny nursery tests were established from 1993 to 2002 at the IRTA nursery beds located in Mas Bové. Prior to sowing, walnut seeds were soaked for $48 \mathrm{~h}$ in a $50 \mathrm{ppm}$ solution of giberellic acid $\left(\mathrm{GA}_{3}\right)$ in order to break physiological dormancy (ALETÀ, 1994). Seeds were sown at a spacing of $30 \times 100 \mathrm{~cm}$ according to a randomised complete block design with four replicates and progenies were randomly allocated within the replicates to 24 -seedling row plots. Rows were covered at each sowing with black plastic strips, $60 \mathrm{~cm}$ wide, to avoid weed infestation. In addition, inter-row space was clean cultivated and two treatments of oxyfluorfen herbicide were applied. Due to the on-going nature of the breeding activities carried out from 1992 (including prospect, evaluation and conservation of parental trees) and the limited extension of the nursery beds, not all families could be evaluated in a single nursery test. In fact, the number of progenies sown each year varied from 6 in 1993 to 19 in 1995 (Table 1). Each progeny was usually sown three times (sowing years) but 14 progenies were only tested twice and the 'Serr' control was sown in all years except in 1993. In total, 24 seedlings/family-row plot x 99 families (including family-year combinations) $\mathrm{x} 4$ replicates $=9,504$ test seedlings were established. Progenies were kept in the nursery for two consecutive years.

\section{Measurements}

Traits collected on each individual seedling at the end of the first and second growing seasons included total height $\left(\mathrm{H}_{1}\right.$ and

Table 1. - Evaluated progenies from 1993 to 2002 in the nursery.

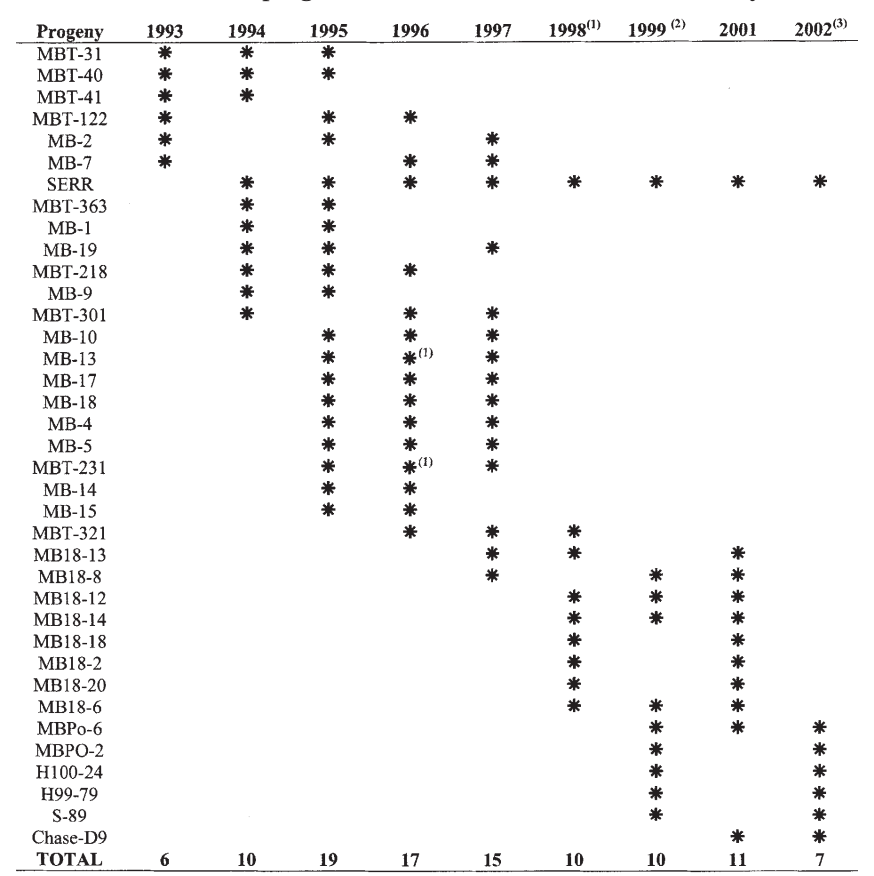

(1): No data available for second growth height and diameter $\left(\mathrm{H}_{2}\right.$ and $\left.\mathrm{D}_{2}\right)$ due to an accident during nursery management.

${ }^{(2)}$ : No data available for second growth height $\left(\mathrm{H}_{2}\right)$ because of autumn frost damage.

(3): Data available only for first growth height and diameter $\left(\mathrm{H}_{1}\right.$ and $\left.\mathrm{D}_{1}\right)$ at the time of the study. 
$\mathrm{H}_{2}$ ) and diameter at $10 \mathrm{~cm}$ from the soil (D1 and D2). Establishment at the plot level (E, \%) was obtained as the ratio of surviving seedlings at the end of the spring in relation to sown seeds (24). Flushing dates (herein $\mathrm{C}_{\mathrm{f}}$, following the nomenclature of phenological stages described by GERMAIN et al. (1999) for Juglans regia) were monitored at the beginning of the second growing season (spring). Variation in seedling growth traits within progenies was assessed by calculation of plot variances for height and diameter in both growing seasons varH $_{1}$, $\operatorname{varH}_{2}, \operatorname{var} \mathrm{D}_{1}, \operatorname{varD}_{2}$ ).

\section{Early selection in the nursery}

An independent culling selection scheme was applied on parental trees using family-mean values for establishment, diameter and total height after evaluation in two to three nursery trials. Flushing was not directly considered in the selection scheme, since the breeding program aims at obtaining a very diverse genetic material regarding phenology, suited for most Spanish growing conditions. Progenies were represented by a minimum of two trials in an attempt to account for possible differences in growing conditions between years and, thus, to obtain a fair characterisation of the parent trees. Family means were obtained as averages across trials for each of the progenies evaluated. Selection occurred in the form of independent culling using specific truncation points for establishment $(\mathrm{E} \geq 40 \%)$, first-year diameter $\left(\mathrm{D}_{1} \geq 12 \mathrm{~mm}\right)$ and first-year height $\left(\mathrm{H}_{1} \geq 25 \mathrm{~cm}\right)$. These values were taken following the only available quality recommendations for $1+0$ walnut plants (BECQUEY, 1997). But growth traits of the second growing season were considered worthwhile to test for possible differences between ages one and two. Parent trees exhibiting a deficient progeny performance on establishment, diameter and height after evaluation in at least two nursery trials (i.e. clearly below their respective truncation points), were discarded for further field testing.

\section{Statistical analysis}

A retrospective analysis of the nine nursery tests conducted over the period 1993-2002 was undertaken in order to obtain unbiased predictions of parental breeding values. The complete data set was very unbalanced given that only a few progenies were grown in every year (Table 1). As a starting point, separate analyses of variance were fitted for each trial using an individual-tree fixed model consisting of a block effect, a family effect, an intra-block error term, and a term accounting for the between-tree within-plot variation. The aim was to check for normality of variables and to collect information on the range of variability between trials for the trait mean $\left(\bar{y}_{j}\right)$, the intrablock error variance $\left(\mathrm{s}^{2}\right)$, and the coefficient of variation (Table 2),

$$
\mathrm{CV}=\left(s_{j} / \bar{y}_{j}\right) \times 100
$$

In forestry, parental breeding value prediction from unbalanced progeny test data is commonly addressed by using mixed models, and then deriving Best Linear Unbiased Predictions (BLUPs) of genetic effects (HENDERSON, 1984; WHITE and HodGe, 1989). A mixed linear model appropriate for single trait, half-sib progeny test data and a randomised complete block design over a number of years is

$$
\mathrm{y}_{\mathrm{ijkl}}=\mu+\mathrm{T}_{\mathrm{i}}+\mathrm{B}_{\mathrm{ij}}+\mathrm{g}_{\mathrm{k}}+\mathrm{gt}_{\mathrm{ik}}+\mathrm{e}_{\mathrm{ijk}}+\mathrm{p}_{\mathrm{ijkl}}
$$

where $\mathrm{y}_{\mathrm{ijkl}}$ is the observation of the $l$ th individual of the $k$ th family in the $j$ th block within the $i$ th trial, $\mu$ is the overall mean, $\mathrm{T}_{\mathrm{i}}$ is the fixed effect of the $i$ th trial, $\mathrm{B}_{\mathrm{ij}}$ is the fixed effect of the $j$ th block within the $i$ th trial, $\mathrm{g}_{\mathrm{k}}$ is the random effect of one half of the $k$ th female's additive genetic effects, $\mathrm{gt}_{\mathrm{ik}}$ is the random effect of interaction between half of the $k$ th female's additive genetic effects and the $i$ th trial, $\mathrm{e}_{\mathrm{ijk}}$ is the random residual effect of the $k$ th family in the $j$ th block within the $i$ th trial, and $\mathrm{p}_{\mathrm{ijkl}}$ is the random tree effect of the $l$ th individual in the ijkth plot.

The single trait mixed model can be extended in order to take into account simultaneously the information available on different characters, thus resulting in a multiple trait analysis. This allows for an increased precision of the predicted genetic effects provided some degree of correlation exists between evaluated traits (WHITE and HodGe, 1989). In this study, a multivariate approach was applied for evaluating first-year and second-year traits separately, which meant considering five characters in the analysis $\left(E, D_{1}, H_{1}\right.$, varD $D_{1}$ and $\operatorname{varH}_{1}$ for the first growing season; $\mathrm{C}_{\mathrm{f}}, \mathrm{D}_{2}, \mathrm{H}_{2}$, $\operatorname{varD}_{2}$ and $\operatorname{varH}_{2}$ for the second growing season). However, data at the individual-tree level were available only for growth traits (D and $\mathrm{H})$ and flushing. Although this inconvenience can be overcome by fitting the corresponding random tree effect simply for the traits of interest in the multivariate analysis, the approach becomes computationally demanding and the model is difficult to converge. Thus, plot means were employed for all traits in order to reduce the size and simplify the number of (co)variance matrices in the analysis on the basis that this decision does not affect the precision of parental breeding value predictions (White and Hodge, 1989). Accordingly, BLUPs of parental breeding values were obtained under the following mixed linear model:

$$
\mathrm{y}=\mathrm{Xb}+\mathrm{Zu}+\mathrm{Wp}+\mathrm{e}
$$

where $\mathrm{y}$ is the vector of the plot mean observations for five characters; $b$ is the vector of fixed effects (trial and block); $u$ is the vector of the random female's genetic effects; $p$ is the vector of random interactions between the female's genetic effects and the trials; e is the vector of random residual deviations of plot effects; X, Z and $\mathrm{W}$ are incidence matrices relating the observa-

\begin{tabular}{|c|c|c|c|c|c|c|c|}
\hline \multirow[b]{2}{*}{ Trait } & \multirow[b]{2}{*}{$\begin{array}{l}\text { Year of } \\
\text { evaluation }\end{array}$} & \multicolumn{2}{|c|}{ Error variance } & \multicolumn{2}{|c|}{ CV $(\%)$} & \multicolumn{2}{|c|}{ Mean } \\
\hline & & Minimum & Maximum & Minimum & Maximum & Minimum & Maximum \\
\hline$E(\%)$ & $1^{\text {st }}$ & 66.3 & 232.1 & 17.1 & 34.5 & 33.4 & 65.4 \\
\hline $\mathrm{D}_{1}(\mathrm{~mm})$ & $1^{\text {st }}$ & 1.4 & 5.2 & 10.0 & 18.8 & 10.2 & 17.4 \\
\hline $\mathrm{H}_{1}(\mathrm{~cm})$ & $1^{\text {st }}$ & 15.1 & 402.8 & 17.6 & 34.7 & 19.7 & 66.6 \\
\hline varb & $1^{\text {st }}$ & 14.8 & 202.2 & 35.3 & 66.0 & 8.8 & 28.2 \\
\hline $\operatorname{varH}_{1}$ & $1^{\text {st }}$ & $6,122.8$ & $746,692.4$ & 57.9 & 107.2 & 94.8 & $1,493.8$ \\
\hline $\mathrm{C}_{\mathrm{f}}\left({ }^{*}\right)$ & $2^{\text {nd }}$ & 4.4 & 14.3 & 2.2 & 3.7 & 96 & 117 \\
\hline $\mathrm{D}_{2}(\mathrm{~mm})$ & $2^{\text {nd }}$ & 5.0 & 23.6 & 8.8 & 18.2 & 22.3 & 30.7 \\
\hline $\mathrm{H}_{2}(\mathrm{~cm})$ & $2^{\text {nd }}$ & 317.7 & $1,438.8$ & 12.5 & 30.0 & 104.2 & 163.8 \\
\hline $\operatorname{varD} D_{2}$ & $2^{\text {nd }}$ & 374.9 & $6,770.6$ & 34.3 & 66.6 & 51.8 & 123.6 \\
\hline $\operatorname{varH}_{2}$ & $2^{\text {nd }}$ & $204,557.7$ & $4,981,266.8$ & 21.0 & 69.7 & $2,152.0$ & $5,078.5$ \\
\hline
\end{tabular}
tions to the model effect.

Table 2. - Summary of information for nine progeny trials.

(*) Julian days. 
All analyses were carried out using the ASREML program (GILMour et al., 2002) which provides residual maximum likelihood (REML) estimates of variance components and BLUPs of random effects.

Inspection of the range of plot error variances across trials (Table 2) indicated that parental genetic effects had been estimated with unequal precision for a number of traits, particularly height $(\mathrm{H})$, diameter variance (varD) and height variance (varH). In the context of multi-environment analysis, the problem of heterogeneity of error variances is commonly handled either by allowing for heterogeneous residual variances over a number of years in the mixed model analysis or by data transformation. The former approach may complicate model convergence in complex data sets, although, on the other hand, a drawback related to the use of transformed data is the need to make inferences on the transformed variable. In this latter case, however, parental ranks are not altered after transformation, making it feasible to re-evaluate family mean-based parental selection by ranking parents based on the BLUP analysis. Therefore, data transformation was selected as the method to remedy error plot variation. The Box-Cox procedure (BOWLEY, 1999), together with an examination of residuals, was used to estimate an adequate data transformation. Hence, a log transformation was found to homogenise variances across trials, and the variables meriting transformation were diameter (D), height $(\mathrm{H})$, diameter variance $(\operatorname{varD})$ and height variance (varH) for both growing seasons.

The degree and similarity of the genetic control of growth traits, establishment and bud phenology were evaluated by estimating family heritabilities, as well as phenotypic, genetic and environmental correlations. Family heritabilities for openpollinated progenies were calculated from variance components as

$$
\mathrm{h}_{\mathrm{f}}^{2}=\frac{0.25 \sigma_{A}^{2}}{\sigma_{P}^{2}}=\frac{\sigma_{F}^{2}}{\sigma_{F}^{2}+\sigma_{F T}^{2} / t+\sigma_{e}^{2} / t b}
$$

where $\sigma_{A}^{2}$ is the additive genetic variance, $\sigma_{P}^{2}$ is the phenotypic variance of family means, $\sigma_{F}^{2}$ is the family variance, $\sigma_{F T}^{2}$ is the family-by-trial year interaction variance, and $\sigma_{e}^{2}$ is the plot error variance. To estimate $h_{f}^{2}, t$ was calculated as the harmonic mean number of trials in which each family was represented (2.6, first growing season; 2.4, second growing season), whereas $b$ is the harmonic mean number of blocks (3.7, first growing season; 2.5, second growing season). Standard errors of family heritabilities were obtained according to GILMOUR et al., 2002.

Genetic, phenotypic, and environmental correlations (and their standard errors) were calculated from the (co)variance component matrices obtained from the multivariate analyses described above (GILMOUR et al., 2002). The general form of a correlation is expressed as

$$
\mathrm{r}_{12}=\frac{\sigma_{12}}{\sqrt{\sigma_{1}^{2} \times \sigma_{2}^{2}}}
$$

where $\sigma_{12}$ stands for the estimated family (phenotypic, environmental) covariance component between traits 1 and $2 ; \sigma_{1}^{2}$ is the family (phenotypic, environmental) variance component estimate of trait 1 ; and $\sigma_{2}^{2}$ is the family (phenotypic, environmental) variance component estimate of trait 2 . Phenotypic (co)variances $\left(\sigma_{\bar{p}}^{2}\right)$ were obtained as for determining the denominator of the heritability estimates. Environmental (co)variances $\left(\sigma_{E}^{2}\right)$ were calculated as

$$
\sigma_{E}^{2}=\sigma_{F T}^{2} / t+\sigma_{e}^{2} / t b
$$

Bivariate analyses were also performed to obtain correlations for traits measured at age 1 and age 2 in the nursery.

\section{Results}

The ranges for average establishment, flushing date, diameter, height, and diameter and height variances over all nursery trials are summarised in Table 2. Except for flushing date, the performance between trials was quite variable, mostly reflecting yearly climatic fluctuations common to Mediterranean areas. Establishment varied from $33.4 \%$ to $65.4 \%$ and flushing dates from 96 to 117 Julian days (i.e. from the beginning until the end of April). However, the largest variation in average performance between trials was found for growth traits and, particularly, for height variances at both ages.

\section{Variance components and family heritabilities}

The variance components estimated from the 1993-2002 series of nursery trials, together with estimates of family heritabilities, are given in Table 3. For growth traits, the dominant variance component was plot error $\left(\sigma_{e}^{2}\right)$, followed by family variance $\left(\sigma_{F}^{2}\right)$ in the first growing season, but the family-bytrial interaction variance $\left(\sigma_{F T}^{2}\right)$ contributed more than $\sigma_{F}^{2}$ to the total phenotypic variance $\left(\sigma_{P}^{2}\right)$ in the second growing season. Conversely, establisment was dominated by $\sigma_{F T}^{2}$ and flushing showed the highest $\sigma_{F}^{2}$ as a percentage of the total phenotypic variance for all traits evaluated.

The large genetic control of flushing date led to a very high heritability estimate (0.93) (Table 3). In contrast, the large family-by-trial and error variances caused a moderate heritability for establisment (0.51). Heritability estimates for growth traits in the first growing season ranged in between, that is, from 0.65 (diameter variance, $\mathrm{LvarD}_{1}$ ) to 0.77 (height, $\mathrm{LH}_{1}$ ). In the second growing season, however, heritability estimates for growth traits decreased to low-moderate values,

Table 3. - Mixed model analysis of several traits: estimates $( \pm \mathrm{SE})$ of phenotypic and genetic variances and heritabilities for nine progeny trials.

\begin{tabular}{|c|c|c|c|c|c|c|c|c|c|c|}
\hline \multirow{3}{*}{ Source } & \multicolumn{10}{|c|}{ Traits } \\
\hline & \multicolumn{5}{|c|}{$1^{\text {st }}$ year } & \multicolumn{5}{|c|}{$2^{\text {nd }}$ year } \\
\hline & $\mathbf{E}$ & $\mathbf{L D}_{1}$ & $\mathbf{L H}_{1}$ & LvarD $_{1}$ & LvarH $_{1}$ & $\mathbf{C}_{\mathrm{f}}$ & $\mathrm{LD}_{2}$ & $\mathbf{L H}_{2}$ & LvarD $_{2}$ & $\mathrm{LvarH}_{2}$ \\
\hline$\sigma_{F}^{2}$ & $\begin{array}{c}71.8 \pm 36.82 \\
(21 \%)\end{array}$ & $\begin{array}{c}0.009 \pm 0.003 \\
(25 \%)\end{array}$ & $\begin{array}{c}0.033 \pm 0.011 \\
(32 \%)\end{array}$ & $\begin{array}{c}0.078 \pm 0.03 \\
(17 \%)\end{array}$ & $\begin{array}{c}0.282 \pm 0.106 \\
(24 \%)\end{array}$ & $\begin{array}{c}68.2 \pm 18.89 \\
(79 \%)\end{array}$ & $\begin{array}{c}0.008 \pm 0.005 \\
(17 \%)\end{array}$ & $\begin{array}{c}0.017 \pm 0.010 \\
(18 \%)\end{array}$ & $\begin{array}{c}0.022 \pm 0.031 \\
(5 \%)\end{array}$ & $\begin{array}{c}0.036 \pm 0.037 \\
(8 \%)\end{array}$ \\
\hline$\sigma_{F T}^{2}$ & $\begin{array}{c}140.1 \pm 32.73 \\
(41 \%)\end{array}$ & $\begin{array}{c}0.002 \pm 0.002 \\
(6 \%)\end{array}$ & $\begin{array}{c}0.010 \pm 0.005 \\
(10 \%)\end{array}$ & $\begin{array}{c}0.012 \pm 0.021 \\
(3 \%)\end{array}$ & $\begin{array}{c}0.162 \pm 0.06 \\
(14 \%)\end{array}$ & $\begin{array}{c}8.9 \pm 2.59 \\
(10 \%)\end{array}$ & $\begin{array}{c}0.018 \pm 0.005 \\
(37 \%)\end{array}$ & $\begin{array}{c}0.030 \pm 0.010 \\
(33 \%)\end{array}$ & $\begin{array}{c}0.051 \pm 0.041 \\
(12 \%)\end{array}$ & $\begin{array}{c}0.082 \pm 0.049 \\
(17 \%)\end{array}$ \\
\hline$\sigma_{e}^{2}$ & $\begin{array}{c}132.3 \pm 11.38 \\
(38 \%)\end{array}$ & $\begin{array}{c}0.025 \pm 0.002 \\
(69 \%)\end{array}$ & $\begin{array}{c}0.059 \pm 0.005 \\
(58 \%)\end{array}$ & $\begin{array}{c}0.362 \pm 0.032 \\
(80 \%)\end{array}$ & $\begin{array}{c}0.727 \pm 0.064 \\
(62 \%)\end{array}$ & $\begin{array}{c}9.2 \pm 0.95 \\
(11 \%)\end{array}$ & $\begin{array}{c}0.022 \pm 0.003 \\
(46 \%)\end{array}$ & $\begin{array}{c}0.045 \pm 0.006 \\
(49 \%)\end{array}$ & $\begin{array}{c}0.348 \pm 0.041 \\
(83 \%)\end{array}$ & $\begin{array}{c}0.354 \pm 0.046 \\
(75 \%)\end{array}$ \\
\hline$\sigma_{P}^{2}$ & $344.2 \pm 40.01$ & $0.036 \pm 0.003$ & $0.102 \pm 0.011$ & $0.452 \pm 0.039$ & $1.171 \pm 0.119$ & $86.3 \pm 18.89$ & $0.048 \pm 0.006$ & $0.092 \pm 0.012$ & $0.421 \pm 0.044$ & $0.472 \pm 0.053$ \\
\hline$\sigma_{\bar{P}}^{2}$ & $139.9 \pm 34.18$ & $0.012 \pm 0.003$ & $0.043 \pm 0.012$ & $0.121 \pm 0.029$ & $0.421 \pm 0.102$ & $73.5+18.82$ & $0.019 \pm 0.005$ & $0.037 \pm 0.01$ & $0.106 \pm 0.026$ & $0.130 \pm 0.032$ \\
\hline$h_{f}^{2}$ & $0.51 \pm 0.153$ & $0.70 \pm 0.091$ & $0.77 \pm 0.072$ & $0.65 \pm 0.108$ & $0.67 \pm 0.108$ & $0.93 \pm 0.024$ & $0.41 \pm 0.184$ & $0.46 \pm 0.173$ & $0.21 \pm 0.254$ & $0.27 \pm 0.229$ \\
\hline
\end{tabular}
Traits evaluated were establisment $(\mathrm{E})$, flushing data $\left(\mathrm{C}_{\mathrm{f}}\right)$, and diameter, height, and their respective variances in the first and second growing seasons on a log basis $\left(\mathrm{LD}_{1}, \mathrm{LH}_{1}, \mathrm{LD}_{2}, \mathrm{LH}_{2}, \mathrm{LvarD}_{1}, \mathrm{LvarD}_{2}, \mathrm{LvarH}_{1}\right.$ and $\left.\mathrm{LvarH}_{2}\right)$.

$(\mathrm{n} \%)=$ Percentage of total phenotypic variance $\sigma_{P}^{2}$.

See text for explanation of variance component subscript. 
Table 4. - Genetic $\left(r_{g}\right)$, phenotypic $\left(r_{p}\right)$ and environmental $\left(r_{e}\right)$ correlations between several traits evaluated in nine progeny trials.

\begin{tabular}{|c|c|c|c|c|c|}
\hline \multicolumn{6}{|c|}{$1^{\text {st }}$ growing year } \\
\hline $\mathbf{E}$ & $\begin{array}{l}r_{z} \pm S E \\
r_{p} \pm S E \\
r_{e} \pm S E\end{array}$ & $\begin{array}{c}\mathbf{L D}_{1} \\
-0.12 \pm 0.300 \\
-0.07 \pm 0.172 \\
0.01 \pm 0.131\end{array}$ & $\begin{array}{c}\mathbf{L H}_{1} \\
-0.06 \pm 0.295 \\
0.07 \pm 0.173 \\
0.32 \pm 0.119\end{array}$ & $\begin{array}{c}\text { LvarD } \\
0.21 \pm 0.312 \\
0.09 \pm 0.170 \\
-0.12 \pm 0.130\end{array}$ & $\begin{array}{c}\text { LvarH }_{\mathbf{1}} \\
0.14 \pm 0.303 \\
0.19 \pm 0.167 \\
0.29 \pm 0.120\end{array}$ \\
\hline $\mathbf{L D}_{\mathbf{1}}$ & $\begin{array}{l}r_{g} \pm S E \\
r_{\rho} \pm S E \\
r_{e} \pm S E\end{array}$ & & $\begin{array}{l}0.81 \pm 0.084 \\
0.80 \pm 0.061 \\
0.78 \pm 0.051\end{array}$ & $\begin{array}{l}0.69 \pm 0.153 \\
0.62 \pm 0.104 \\
0.50 \pm 0.097\end{array}$ & $\begin{array}{l}0.79 \pm 0.104 \\
0.74 \pm 0.075 \\
0.64 \pm 0.076\end{array}$ \\
\hline $\mathbf{L H}_{1}$ & $\begin{array}{l}r_{g} \pm S E \\
r_{p} \pm S E \\
r_{e} \pm S E\end{array}$ & & & $\begin{array}{l}0.72 \pm 0.145 \\
0.62 \pm 0.106 \\
0.40 \pm 0.109\end{array}$ & $\begin{array}{l}0.98 \pm 0.033 \\
0.91 \pm 0.029 \\
0.76 \pm 0.054\end{array}$ \\
\hline LvarD $_{1}$ & $\begin{array}{l}r_{p} \pm S E \\
r_{p} \pm S E \\
r_{e} \pm S E\end{array}$ & & & & $\begin{array}{l}0.78 \pm 0.127 \\
0.71 \pm 0.086 \\
0.57 \pm 0.088\end{array}$ \\
\hline \multicolumn{6}{|c|}{$2^{\text {nd }}$ growing year } \\
\hline & & $\overline{\mathbf{L} \mathbf{D}_{2}}$ & $\mathrm{LH}_{2}$ & LvarD $_{2}$ & $\mathrm{LvarH}_{2}$ \\
\hline Cf & $\begin{array}{l}r_{R} \pm S E \\
r_{p} \pm S E \\
r_{e} \pm S E\end{array}$ & $\begin{array}{l}-1.22 \pm 0.214 \\
-0.77 \pm 0.066 \\
-0.08 \pm 0.147\end{array}$ & $\begin{array}{c}-1.10 \pm 0.170 \\
-0.72 \pm 0.082 \\
0.00 \pm 0.150\end{array}$ & $\begin{array}{l}-1.01+1.156 \\
-0.36 \pm 0.150 \\
-0.07 \pm 0.157\end{array}$ & $\begin{array}{c}-1.25 \pm 0.495 \\
-0.61 \pm 0.109 \\
0.11 \pm 0.144\end{array}$ \\
\hline $\mathrm{LD}_{2}$ & $\begin{array}{l}r_{k} \pm \mathrm{SE} \\
r_{p} \pm \mathrm{SE} \\
r_{e} \pm \mathrm{SE}\end{array}$ & & $\begin{array}{l}0.92 \pm 0.117 \\
0.85 \pm 0.051 \\
0.81 \pm 0.053\end{array}$ & $\begin{array}{l}0.91 \pm 0.431 \\
0.53 \pm 0.129 \\
0.33 \pm 0.144\end{array}$ & $\begin{array}{l}1.36 \pm 0.509 \\
0.66 \pm 0.096 \\
0.31 \pm 0.132\end{array}$ \\
\hline $\mathrm{LH}_{2}$ & $\begin{array}{l}r_{g} \pm S E \\
r_{p} \pm S E \\
r_{c} \pm S E\end{array}$ & & & $\begin{array}{l}0.32 \pm 0.521 \\
0.34 \pm 0.167 \\
0.39 \pm 0.139\end{array}$ & $\begin{array}{l}1.08 \pm 0.329 \\
0.70 \pm 0.088 \\
0.51 \pm 0.107\end{array}$ \\
\hline LvarD $_{2}$ & $\begin{array}{l}r_{R} \pm \mathrm{SE} \\
r_{p} \pm \mathrm{SE} \\
r_{e} \pm \mathrm{SE}\end{array}$ & & & & $\begin{array}{l}0.73 \pm 0.366 \\
0.73 \pm 0.085 \\
0.74 \pm 0.073\end{array}$ \\
\hline
\end{tabular}

especially for diameter and height variances $(0.21$ and 0.27 , respectively).

\section{Correlations}

Genetic $\left(\mathrm{r}_{\mathrm{g}}\right)$, phenotypic $\left(\mathrm{r}_{\mathrm{p}}\right)$, and environmental $\left(\mathrm{r}_{\mathrm{e}}\right)$ correlations among traits are shown in Table 4. Growth traits in both growing seasons, including diameter and height within-family variation (LvarD and LvarH, respectively), were highly correlated genetically, phenotypically and environmentally. Thus, high growth was associated with large family heterogeneity in height and diameter at both the genetic and environmental level. This was probably the consequence of scale effects, that is, an increase in variance when the family mean increased. In other cases, $r_{g}, r_{p}$, and $r_{e}$ differed in magnitude and even in sign. For example, establishment (E) was genetically unrelated to growth traits, but there was a positive environmental relationship between $\mathrm{E}$ and $\mathrm{LH}_{1}$ or $\mathrm{LvarH}_{1}$. In addition, flushing $\left(\mathrm{C}_{\mathrm{f}}\right)$ was negatively associated genetically with growth traits, but unrelated to them environmentally. These results indicated that, in both cases $\left(\mathrm{E}\right.$ and $\mathrm{C}_{\mathrm{f}}$ ), relationships with growth traits were differentially affected by genetic and environmental sources of variation. Correlations between growth traits measured in the first and second growing seasons are shown in Table 5. In all cases, $\mathrm{r}_{\mathrm{g}}, \mathrm{r}_{\mathrm{p}}$, and $\mathrm{r}_{\mathrm{e}}$ had the same positive sign

Table 5. - Genetic $\left(r_{g}\right)$, phenotypic $\left(r_{p}\right)$ and environmental $\left(r_{e}\right)$ correlations between first and second year growth traits evaluated in nine progeny trials.

\begin{tabular}{|c|c|c|c|c|c|}
\hline \multicolumn{2}{|c|}{$1^{\text {st }}$ growing year } & \multicolumn{4}{|c|}{$2^{\text {nd }}$ growing year } \\
\hline $\mathbf{L D}_{\mathbf{1}}$ & $\begin{array}{l}r_{g} \pm S E \\
r_{p} \pm S E \\
r_{c} \pm S E\end{array}$ & $\begin{array}{c}\mathbf{L D}_{\mathbf{2}} \\
0.84 \pm 0.108 \\
0.83 \pm 0.059 \\
0.85 \pm 0.049\end{array}$ & $\begin{array}{c}\mathbf{L H}_{2} \\
\cdots\end{array}$ & $\begin{array}{c}\text { LvarD }_{2} \\
---\end{array}$ & $\begin{array}{c}\text { LvarH }_{2} \\
\ldots-\end{array}$ \\
\hline $\mathbf{L H}_{\mathbf{1}}$ & $\begin{array}{l}r_{g} \pm S E \\
r_{p} \pm S E \\
r_{e} \pm S E \\
\end{array}$ & -- & $\begin{array}{l}0.88 \pm 0.087 \\
0.85 \pm 0.056 \\
0.86 \pm 0.047 \\
\end{array}$ & --- & $\cdots$ \\
\hline LvarD $_{1}$ & $\begin{array}{l}r_{g} \pm S E \\
r_{p} \pm S E \\
r_{t} \pm S E \\
\end{array}$ & $\cdots$ & $\cdots$ & $\begin{array}{l}1.17 \pm 0.214 \\
0.81 \pm 0.058 \\
0.59 \pm 0.101\end{array}$ & --- \\
\hline Lvar $_{1}$ & $\begin{array}{l}r_{R} \pm S E \\
r_{p} \pm S E \\
r_{g} \pm S E\end{array}$ & --- & --- & --- & $\begin{array}{l}1.01 \pm 0.159 \\
0.75 \pm 0.082 \\
0.44 \pm 0.124\end{array}$ \\
\hline
\end{tabular}

and did not differ much in magnitude, with values close to unity.

\section{Selection}

The result of performing independent culling selection, in terms of number and type of selected parent trees, was examined with two different strategies. For independent culling based on mean family performance (mean-based strategy, carried out routinely in the breeding program), 26 out of 37 progenies were rejected according to establishment ( $\mathrm{E} \geq 40 \%)$, firstyear diameter $\left(\mathrm{D}_{1} \geq 12 \mathrm{~mm}\right)$ and first-year height $\left(\mathrm{H}_{1} \geq 25 \mathrm{~cm}\right)$ (Table 6). In fact, it was unnecessary to consider selection for height because of redundancy with that for diameter. This led to an overall selection proportion of $30 \%$. For $\mathrm{E}$ and $\mathrm{D}_{1}$ considered independently, 25 and 22 progenies, respectively, exceeded the fixed threshold for each trait (which was equal to a selection proportion of $70 \%$ and $60 \%$ for $\mathrm{E}$ and $\mathrm{D}_{1}$, respectively).

On the other hand, for independent culling based on retrospective selection using a mixed model analysis over all nursery trials (BLUP-based strategy), a selection proportion of $70 \%$ and $60 \%$, respectively, was applied to the unbiased predictions (BLUPs) of parental breeding values for $\mathrm{E}$ and $\mathrm{LD}_{1}$ (Table 6). This was undertaken to facilitate a direct comparison between the two selection strategies. In other words, the proportion of culled progenies for both $\mathrm{E}$ and $\mathrm{D}_{1}$, according to the meanbased strategy, was maintained when selection was applied retrospectively to the predicted parental breeding values. As a

Table 6. - Results of independent culling selection for establisment and diameter in the first year $\left(D_{1}\right)$ based on either mean family performance or BLUP-based estimates of breeding values. Bold figures correspond to selected progenies for the considered trait. Underlined progenies are those chosen under both types of selection.

\begin{tabular}{|c|c|c|}
\hline \multirow[b]{2}{*}{ Progeny } & \multicolumn{2}{|c|}{ Mean performance } \\
\hline & $\begin{array}{c}\text { Establisment } \\
(\%)\end{array}$ & $D_{1}(\mathrm{~mm})$ \\
\hline $\mathrm{H} 100-24$ & 87.1 & 14.6 \\
\hline MB-7 & 73.0 & 11.7 \\
\hline MB-5 & 62.2 & 9.2 \\
\hline MBT-301 & 60.6 & 13.4 \\
\hline MBT-4I & 58.5 & 11.9 \\
\hline H99-79 & 58.4 & 14.3 \\
\hline$\underline{\text { MBT-40 }}$ & 56.7 & 12.0 \\
\hline MBT-31 & 56.3 & 12.4 \\
\hline CHASE-D9 & 55.5 & 11.3 \\
\hline MB-18 & 55.1 & 11.3 \\
\hline$\underline{\text { SERR }}$ & 53.1 & 13.8 \\
\hline MB18-14 & 52.9 & 13.9 \\
\hline MB-4 & 52.2 & 11.1 \\
\hline MBT-218 & 52.1 & 12.4 \\
\hline MB-15 & 51.6 & 10.3 \\
\hline MB-19 & 49.0 & 11.5 \\
\hline MBT-122 & 46.7 & 14.1 \\
\hline MBPO-2 & 46.5 & 13.1 \\
\hline MB-9 & 45.4 & 7.8 \\
\hline MB-17 & 45.0 & 10.7 \\
\hline MB-2 & 44.8 & 11.9 \\
\hline MB-10 & 43.8 & 11.8 \\
\hline MBT-321 & 43.8 & 12.4 \\
\hline MB-14 & 43.8 & 10.2 \\
\hline MBT-363 & 43.5 & 11.6 \\
\hline MBPo-6 & 38.3 & 14.5 \\
\hline MB18-20 & 38.1 & 14.0 \\
\hline S-89 & 38.0 & 14.5 \\
\hline MB18-18 & 37.1 & 13.5 \\
\hline MB18-12 & 35.9 & 15.4 \\
\hline MB-1 & 35.0 & 8.5 \\
\hline MB-13 & 33.1 & 12.0 \\
\hline MB18-6 & 33.1 & 14.1 \\
\hline MB18-13 & 32.4 & 13.8 \\
\hline MB18-8 & 29.9 & 15.1 \\
\hline MBT-231 & 23.1 & 12.2 \\
\hline MB18-2 & 20.0 & 14.3 \\
\hline
\end{tabular}

\begin{tabular}{|c|c|c|}
\hline \multirow[b]{2}{*}{ Progeny } & \multicolumn{2}{|c|}{ Breeding value } \\
\hline & $\begin{array}{c}\text { Establisment } \\
(\%)\end{array}$ & $\mathrm{LD}_{1}(\log \mathrm{mm})$ \\
\hline H100-24 & 17.4 & 0.05 \\
\hline MB-7 & 10.9 & -0.02 \\
\hline MB-5 & 9.3 & -0.17 \\
\hline $\begin{array}{l}\text { MB18-14 } \\
\text { MBT-301 }\end{array}$ & $\begin{array}{l}6.0 \\
5.7\end{array}$ & $\begin{array}{r}-0.04 \\
0.09\end{array}$ \\
\hline MB-18 & 5.3 & -0.01 \\
\hline SERR & 5.2 & 0.09 \\
\hline H99-79 & 4.8 & 0.03 \\
\hline CHASE-D 9 & 4.6 & -0.08 \\
\hline MB-4 & 3.9 & -0.03 \\
\hline MB-15 & 1.7 & -0.09 \\
\hline MB-19 & 1.7 & 0.03 \\
\hline MBT -40 & 1.0 & 0.06 \\
\hline MBT-321 & 0.8 & 0.02 \\
\hline MBT-31 & 0.7 & 0.08 \\
\hline MBT-218 & 0.6 & 0.07 \\
\hline MB-17 & 0.1 & -0.06 \\
\hline MBPo-2 & -0.4 & -0.03 \\
\hline MB-10 & -0.6 & 0.01 \\
\hline MBT-41 & -1.2 & 0.03 \\
\hline MB18-20 & -1.3 & 0.02 \\
\hline MB-14 & -1.7 & -0.07 \\
\hline MB18-18 & -1.7 & -0.02 \\
\hline MB-9 & -1.9 & -0.23 \\
\hline MB-2 & -2.1 & 0.04 \\
\hline MBT-363 & -2.7 & 0.05 \\
\hline MB18-12 & -3.1 & 0.04 \\
\hline MBT-122 & -3.7 & 0.15 \\
\hline S-89 & -4.1 & 0.06 \\
\hline MB18-13 & -4.3 & 0.05 \\
\hline MB18-6 & -4.7 & -0.03 \\
\hline MBPo-6 & -5.0 & 0.01 \\
\hline MB-1 & -6.4 & -0.16 \\
\hline MB-13 & -6.6 & 0.02 \\
\hline MB18-8 & -7.2 & 0.02 \\
\hline MB18-2 & -9.2 & 0.02 \\
\hline MBT-231 & -11.5 & 0.04 \\
\hline
\end{tabular}

Selection proportions of $70 \%$ and $60 \%$ for $\mathrm{S}$ and $\mathrm{LD}_{1}$, respectively. 
consequence, a total of 13 out of 37 parent trees simultaneously accomplished the selection proportions of $70 \%$ and $60 \%$ for $\mathrm{E}$ and $\mathrm{D}_{1}$, respectively (selection based on either $\mathrm{D}_{1}$ or $\mathrm{H}_{1}$ gave identical culled parent trees). This led to an overall selection proportion of $35 \%$. Thus, independent-culling selection based on mean family performance was overall a bit more restrictive than that applied to the BLUPs parental breeding values once all progenies were evaluated together.

Eight parent trees were selected regardless of selection strategy but some others were variously culled or accepted (Table 6): 'MBT-122', 'MB18-14' and 'MBPO-2' were retained under the family mean-based strategy, but refused using BLUPs due to comparatively lower $\mathrm{E}$ or $\mathrm{LD}_{1}$ predictions. On the other hand, five parents ('MBT-41', 'MB19', 'MB2', 'MB10' and 'MB18-20') that were retained due to large breeding value predictions did not exhibit a high enough mean family performance for either $\mathrm{E}$ or $\mathrm{LD}_{1}$ and, accordingly, were not included among the 11 selected parents in the mean-based strategy. Therefore, meanbased and BLUP-based independent culling selections produced somewhat contrasting results regarding parental identification with the largest progeny potential for establishment and growth in the nursery. This outcome is also presented in Figure $1 a$ and $1 b$, in which changes in parental ranking for establishment and diameter under both selection strategies are depicted. Although Spearman's rank correlations were all posi-

\section{$r_{k}=0.90(P<0.01)$}

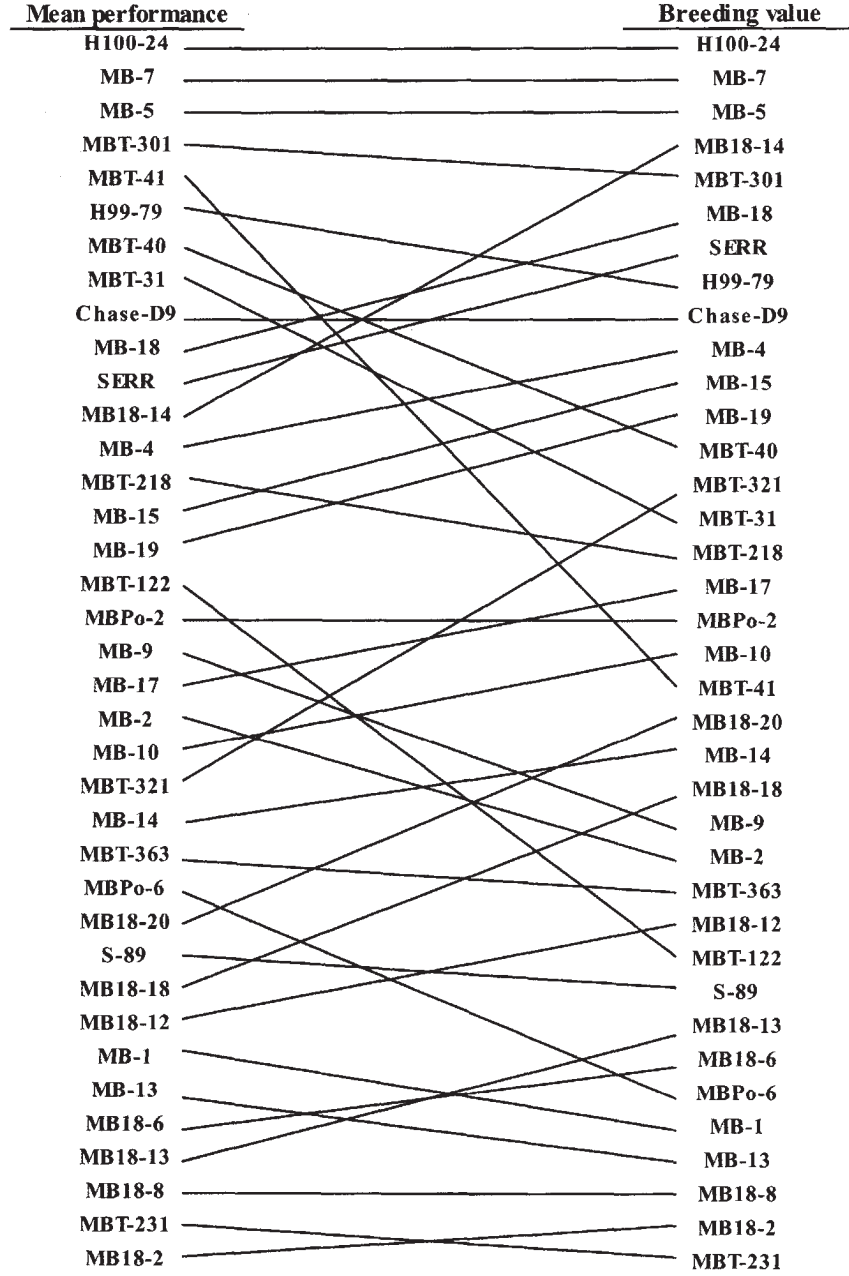

Figure 1a. - Progeny ranking considering family mean performance and estimated breeding values of establishment. Spearman correlation $\left(\mathrm{r}_{\mathrm{k}}\right)$.

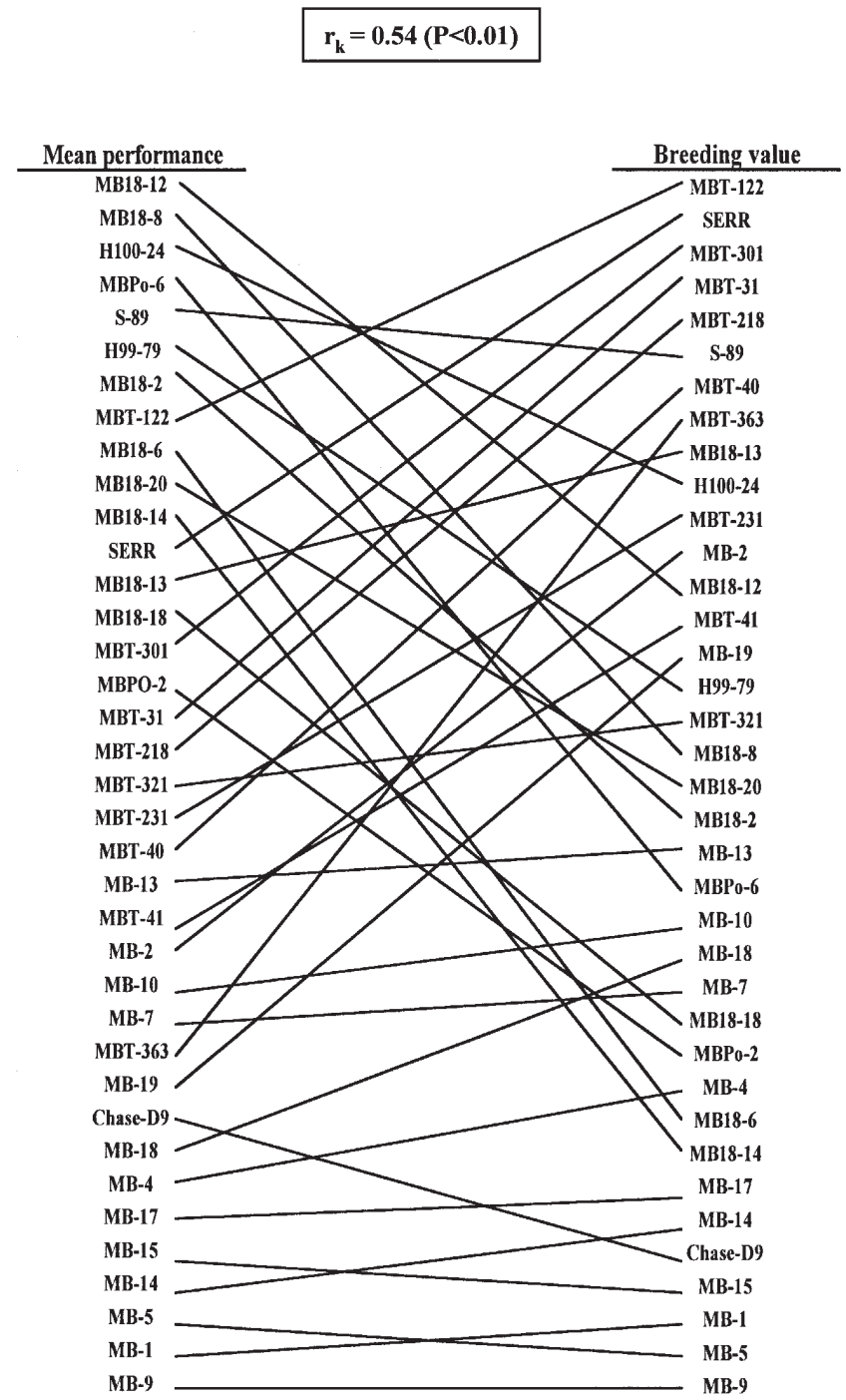

Figure 1b. - Progeny ranking considering family mean performance and estimated breeding values of $\mathrm{LD}_{1}$. Spearman correlation $\left(r_{k}\right)$.

tive and significant, large crossover-type ranking variations among parents were present, especially for diameter, as also indicated by a lower correlation. These results highlight the potential of performing a retrospective evaluation of selection to support or, otherwise, disregard the initial decision of culling parents based on their average progeny performance in several nursery trials.

\section{Discussion}

For Juglans regia, there is little published information available on progeny evaluation. In addition the focus of these studies is on juvenile stages of development, for example, one or two-year old seedlings in the nursery (FERNÁNDEZ and PEREIRA, 1997; DíAZ and FERNÁNDEZ, 2001). Traits evaluated are usually restricted to growth parameters such as height and diameter. In this study, other valuable characteristics for walnut cultivation such as establishment and phenology (flushing date) have been monitored, along with an assessment of within-progeny variability for growth performance. This latter feature is of utmost importance for breeding due to the need for homogeneous progenies in order to standardise management practices such as pruning and also to obtain commercial benefit from a standard end-product. However, it was not included in the selection scheme owing to the lack of information on meaning- 
ful culling values for traits indicating within-family variation in seedling growth.

The genetic control of most traits was quite high considering both family variances and heritability estimates. This was, however, expected for flushing time, thereby confirming previous estimates of individual heritabilities obtained for J. regia devoted to nut production (HANSCHE et al., 1972; GERMAIN, 1997). Moreover, first-year family heritabilities estimated here for height are similar to those estimated by RINK and KUNG (1995) for Juglans nigra. Undoubtedly, the uniform site conditions typical of nursery tests favoured the expression of genetic mechanisms controlling growth traits otherwise subjected to a much larger environmental influence. Nevertheless, the sharp decrease in second-year heritabilities suggests the incidence of maternal effects in the expression of growth traits in the first year (DÍAZ and FERNÁNDEZ, 2001). On the other hand, the diameter showed slightly lower heritabilities than height at both ages investigated, as reported elsewhere for other forest species (XIE and YING, 1996; CoRnelius, 1994).

From a breeding point of view, the most noticeable outcome brought about by the extent of genetic correlations is the independence of growth traits from the seedling establishment percentage. This observation indicates the feasibility of performing simultaneous selection for both traits, which are highly rewarded in large-scale commercial production of walnut seedlings. The strong genetic correlations involving traits other than establishment suggest an inability to apply efficiently selection for more than one feature at the same time. For example, the identification of parent trees simultaneously producing high-growing and uniform progenies seems to be difficult since the fastest growing families tended to present the highest variability among individuals. In addition, early-flushing families exhibited higher growth, suggesting a strongly biased selection towards precocious progenies in the nursery when growth is used as the only selection criterion. The great relevance of late flushing genotypes in mountainous areas of Spain means that we have to consider, when culling the worst families, the maintenance of progenies such as 'MB-7' or 'MB17' that have an appropriate establishment but do not show enough growth due to their late phenology.

Examination of age-age correlations for growth traits suggests similar parental selection for both the first and second growing seasons in the nursery. Accordingly, second year evaluation in the nursery can probably be reduced to flushing time without missing valuable information on growth performance. This would be highly desirable in order to avoid seedling exposition to detrimental factors for growth, such as incidence of late frosts or weed infestation. In this regard, autumn frost prevented a record of second year growth in one of the trials evaluated (Table 1). It should be pointed out, however, that age-age genetic correlations tend to decrease sharply in mature Juglans nigra (RINK and KUNG, 1995), with estimated values of 0.1 and 0.2 between age 1 and age 20 , and age 2 and age 20 , respectively, as obtained in an individual-tree basis. For this reason, it is still unknown whether early testing in Juglans regia may be a preferred strategy to identify and cull poor-performing genotypes prior to field testing (the so-called multiplestage selection) or whether it should be a tool to select superior genotypes in order to shorten generation intervals (early single-stage selection) (ADAMS et al., 2001).

Changes in parental ranking after fitting a mixed linear model to the nursery data were considerable. Simple averages are biased estimators of parental means because they are greatly affected by large differences between trials. In contrast, the best linear unbiased predictors of parental breeding values are most adequate for severely unbalanced data (WHITE and HoDGE, 1989). For example, the outstanding growth monitored in 1999 (Table 1), which should be attributed to exceptionally favourable environmental and/or management circumstances, favoured selection and overall ranking (based on simple averages) of progenies evaluated in that season. This effect, however, was considerably amended by the mixed model analysis (Figures $1 a$ and $1 b$ ). The disagreement in ranking genotypes between both selection strategies (mean-based and BLUPbased), together with the larger proportion of culled progenies in the former (about 70\%), suggests a sizeable loss of genetic gain by using unadjusted parental means. The convenience of applying low selection intensities in nursery tests has already been pointed out by WU (1998) who found, using a culling proportion of $70 \%$ on diameter for lodgepole pine accompanied by further selection $(10 \%)$ on height in the field, a total genetic gain of $-7 \%$. In another early testing study of Douglas-fir, ADAMS et al. (2001) indicated that a culling proportion of $25 \%$ in the nursery, followed by field testing, would not reduce genetic gain as compared with direct family selection in the field. Although precise information is lacking for Juglans sp., it may be feasible to expect similar results in the walnut tree (RINK and Clausen, 1989; RINK and KUnG, 1995). On the other hand, the redundancy brought about by both growth traits (height and diameter) in the independent culling selection strategy indicates that growth performance can be evaluated by any of the traits with similar results, regardless of the estimation method of parental values.

In the context of the breeding program, it may seem largely unsatisfactory that only MBT-122 exceeded Serr, our reference material, in growth traits. Despite its exceptional nursery performance, it should be noted that Serr (a highly vigorous rootstock used in nut plantations) has proved inappropriate for wood production because of deficient adult tree form and a large tendency for forking.

So far, the retrospective evaluation of parental selection in the nursery suggests that the actual selection scheme should be reconsidered. On the one hand, the proportion of culled families needs to be reduced to accommodate a larger number of progenies for testing in the field and, thus, to avoid sacrificing valuable parental material. However, this implies changes in the criteria used for culling families, which follow general quality recommendations for $1+0$ walnut plants, as stated by BECQUEY (1997). Current thresholds for growth, which have shown adequacy for testing fast growing hybrid material involving species such as J. regia, J. nigra or J. major, are probably too restrictive for the less growing J. regia. Selection of a higher number of progenies in the nursery, representing a high variability in phenology, can be subsequently achieved by redefining current culling levels for both diameter and establishment. On the other hand, it is advisable to estimate breeding values a posteriori using BLUPs in order to recover valuable material otherwise refused if nursery data over a number of years is not considered. While continuous progeny testing performed over a number of years facilitates the evaluation of incoming parent trees, reduces nursery test size and makes more precise and complete data recording feasible, the present study has clearly demonstrated the convenience to handle such unbalanced data sets through a mixed model framework.

\section{Aknowledgements}

These research activities were supported by two European projects: AIR3-CT92-0142 (1993-1996) and FAIR-CT96-1887 (1997-2000), and a Spanish National project from the Ministry of Science and Technology, INIA-SC00-006-C2-1 (2000-2003). The authors thank an anonymous reviewer for helpful comments and suggestions on the manuscript. 


\section{Literature}

Adams, W. T., Aitken, S. N., Joyce, D. G., Howe, G. T. and Vargas-HerNANDEZ, J.: Evaluating efficacy of early testing for stem growth in coastal Douglas-fir. Silvae Genetica 50: 167-175 (2001). — ALETÀ, N.: La multiplicación del nogal. Producción y economía de frutos secos. Postgraduate curs FAO-CIHEAM. Reus 7-18 nov. (1994). - AlETÀ, N., Ninot, A. and VolTAS, J.: Caracterización del comportamiento agroforestal de 12 genotipos de nogal (Juglans sp.) en dos localidades de Cataluña. Investi. Agrar: Sist. Recur. For. 12(1): 39-50 (2003). - BECQUEY, J.: Les noyers à bois. Ed. IDF. 144pp (1997). - BowlEY, S. R.: A hitchhiker's guide to statistics in plant biology. Ed. Any Old Subject Books 250pp (1999) - BResnan, D. F., Geyer, W. A., LynCH, K. D. and RinK, G.: Black walnut provenance performance in Kansas. North. J. Appl. For. 9(2): 43-46 (1992). - BResnan, D. F., RinK, G., Diebel, K. E. and GEYER, W. A.: Black walnut performance in seven 22-year-old plantations. Silvae Genetica 43: 246-252 (1994). — CoRNELIUS, J.: Heritabilities and additive genetic coefficients of variation in forest trees. Can. J. For Res. 24: 372-379 (1994). - DíAZ, R. and FernÁNDEZ, J.: Evaluación de un ensayo de progenie de Juglans regia L. En Galicia. Proceedings of III Congreso Forestal Español, Granada (2001). - FERnÁndEZ, J. and PEREIRA, S.: Genetic control of growth in Juglans regia seedlings from open pollinated families of different provenances. Acta Horticulturae 442. 69-75 (1997) - FrenshaM, A. B. BARR, A. R., CULLIS, B. R and Pelham, S. D.: A mixed model analysis of 10 years of oat evaluation data: use of agronomic information to explain genotype by environmen interaction. Euphytica 99: 43-56 (1998). — GERMAIN, E.: Genetic improvement of the Persian walnut (Juglans regia L.). Acta Horticulturae 442: 21-31 (1997). - Germain, E., Prunet, J. P. and Garcin, A.: Le noyer. CTIFL. 279 pp (1999). - Germain, E., Aletà, N., Ninot, A. Rouskas, D., Zakinthinos, G., Gomes-Pereira, J. A., Monastra, F. and Limongeldi, F.: Prospections réalisées dans les populations de semis de noyer d'Espagne, de Grèce, d'Italie et du Portugal: caractéristiques des populations et description en collections d'études des préselection issues de ces prospections. Options Mediterranéennes 16: 9-40 (1997).
- Gilmour, A. R., Gogel, B. J., Cullis, B. R., Welham, S. J. and THOMPSON, R. ASReml User guide release 1.0. VSN International Ltd. Hemel Hempstead. UK. 267 pp (2002). - Hansche, P. E., Beres, V. and FORDE, H. I.: Estimates of quantitative genetic properties of walnut and their implications for cultivar improvement. J. Amer. Soc. Hort. Sci. 97(2): 279-285 (1972). - Henderson, C. R.: Applications of linear models in animal breeding. University of Guelph. Ontario. 462 pp (1984). - Leslie, C. and McGranahan, G.: The origin of the walnut. In: Walnut production manual. Ramos, D. ed. University of California. Publication 3373: 3-7. (1998). - MAlvolti, M. E., Beritognolo, I. and SPADA, M.: Diversita genetica in Juglans regia L: Valutazione delle risorse genetiche in Europa per uno sviluppo agricolo e forestale sostenibile. Sherwood 8: 11-17 (1996). - Muldin, T. J., AdAms, G.W. Simpson, J. D., Tosh, K. J. and Greenwood, M. S.: Genetic parameters and correlations in tests of open pollinated black spruce families in field and retrospective nursery test environments. Can. J. For. Res. 25: 270285 (1995). - PATTERSon, H. D: Analysis of series of variety trials. In Statistical methods for plant variety evaluation. KEMPTON R. A and Fox P. N. eds. Chapman and Hall. (1997). - RINK, G.: Trends in genetic control of juvenile walnut height growth. Forest. Sci. 30(3): 821-827 (1984), - RinK, G. and Clausen, K. E.: Site and age effects on genotypic control of juvenile Juglans nigra L. tree height. Silvae Genetica 38(1): 17-21 (1989). - Rink, G. and KunG, F. H.: Age trends in genetic control of Juglans nigra L. height growth. Proceedings $10^{\text {th }}$ Central Hardwood Forest Conference, Morgantown, West Virginia, 5-8 March. Technical Report Northeastern Forest Experiment Station. USDA Forest Service. No NE-197: 247-255 (1995). - White, T. L. and Hodge, G. R.: Predicting breeding values with applications in forest tree improvement. Kluwer Academic Publ. 367 pp (1989). - Wu, H. X.: Study of early selection in tree breeding. 1. Advantage of early selection through increase of selection intensity and reduction of field test size. Silvae Genetica 47: 146-155 (1998). - XIE, C. Y. and YING, C. C.: Heritabilities, age-age correlations, and early selection in lodgepole pine (Pinus contorta ssp. Latifolia). Silvae Genetica 45: 101-107 (1996).

\title{
Genetic Variation in Growth and Blister-Rust Resistance in a Pinus strobus $\mathrm{x}$ P. wallichiana Hybrid Population
}

\author{
By I. BLADA
}

Forest Research and Management Institute, Sos. Stefanesti 128, P. Office 11, Bucharest, Romania

(Received 27th January 2004)

\section{Summary}

This experiment consists in a controlled crossing according to a factorial design performed between 7 female trees of $P$. strobus and 4 male trees of $P$. wallichiana to combine the rapid growth of former species with high resistance to Cronartium ribicola of the latter one. The hybrid families were artificially inoculated at age 2, and field planted at age 6. Blister rust resistance (BRR), tree survival (TS), total height growth, $(\mathrm{H})$ annual height growth (h), diameter (D), basal area (BA), stem volume $(\mathrm{V})$, stems straightness (SS) and branch thickness (BT) were the traits measured at age 17. Statistical analysis produced the results presented below.

Significant $(\mathrm{p}<0.05)$ and highly significant $(\mathrm{p}<0.01$; $p<0.001$ ) differences were found among hybrid families. Differences among female effects were highly significant $(p<0.001)$ for all tested traits including BRR, suggesting that nuclear additive genes controlled these traits. Significant differences were found among male parents for $\mathrm{H}$ but no significant differences for BRR; therefore, all four male parents transmitted a similar level of resistance. The ratio $\sigma_{\mathrm{GCA}}^{2} / \sigma_{\mathrm{SCA}}^{2}$ variance accounted for 8.1 for BRR, 8.5 for $\mathrm{H}, 3.5$ for V, 9.3 for SS and 1.9 for BT. Similarly, the ratios of $\sigma_{\mathrm{GCA}-\mathrm{F}}^{2} / \sigma_{\mathrm{GCA}-\mathrm{M}}^{2}$ variance due to female parents were 70.5 for BRR, 23.6 for $\mathrm{H}, 1.0$ for $\mathrm{V}, 0.4$ for SS and 1.0 for BT, were found. Narrow-sense heritabilities, at individual level, were low to moderately high, ranging between 0.085 for BT and 0.421 for BRR. By comparison with the mean of $P$. strobus parent species, the BRR heterosis was highly positive, but negative for all growth traits. If the hybrids will be used in operational planting programs, a significant genetic gain for BRR and growth traits could be achieved.

Key words: Pinus strobus, $P$. wallichiana, Cronartium ribicola, hybrid, heterosis, additive variance, heritability, genetic correlation, genetic gain.

\section{Introduction}

Blister rust (Cronartium ribicola FisCH. ex RABENH.) caused severe damages throughout the commercial range of eastern white pine (Pinus. monticola DougL.) and over extensive high- 